\title{
Peningkatan Produktivitas dan Efisiensi Konsumsi Air Tanaman Bayam (Amaranthus tricolor L.) pada Teknik Hidroponik melalui Pengaturan Populasi Tanaman
}

\section{Productivity Increasement and Water Consumption Efficiency of Amaranth (Amaranthus tricolor L.) in Hydroponic Technique by Plant Population Arrangement}

\author{
Ade Wachjar*, Rizkiana Anggayuhlin \\ Departemen Agronomi dan Hortikultura, Fakultas Pertanian, Institut Pertanian Bogor \\ (Bogor Agricultural University), Jl. Meranti, Kampus IPB Darmaga, Bogor 16680, Indonesia \\ Telp.\&Faks.62-251-8629353 e-mail agronipb@indo.net.id
}

\begin{abstract}
The purpose of the research was to study the effect of plant population on productivity and water consumption of amaranth in hydroponic technique. Research was conducted in Parung Farm, Bogor, from April to May 2011.. The research used Nutrient Film Technique (NFT) hydroponic system that modificated with gravel as its planting medium. The research was arranged in Randomized Complete Block Design with one factor, i.e. , 1, 2, 3, or 4 seedling numbers per hole. The research was divided into two experiment. The first was experiment to study the effect of plant population on plant productivity, and the second was experiment to study the effect of plant population on water consumption of plant.The result showed that plant with one seedling in the planting hole gave the best response on growth of amaranth (plant height, leaves numbers), but for plant productivity, the best result was obtained from plant with three seedlings in the planting hole. Water consumption was highest in plants with one seed per planting hole. Apparently, the more the population, the less consumption of water is needed. This is due to poor root conditions in densely populated. Plant roots will adversely affect the absorption of water
\end{abstract}

Keywords : gravel, hydroponic kit, seedling numbers, the planting hole

\section{ABSTRAK}

Penelitian dilakukan di Parung Farm, Bogor, dari bulan April sampai Mei 2011. Tujuan dari penelitian ini adalah untuk mengetahui populasi optimum tanaman bayam pada teknik hidroponik yang menghasilkan produktivitas maksimum dan mengetahui pengaruh populasi terhadap kebutuhan air tanaman bayam pada teknik hidroponik. Penelitian ini menggunakan Teknik Film Nutrisi (NFT) sistem hidroponik yang dimodifikasi dengan kerikil sebagai media tanamnya. Penelitian ini disusun dalam Rancangan Acak Lengkap dengan satu faktor. Faktor tersebut adalah nomor bibit: $P 1=1, P 2=2, P 3=3, P 4=4$. Penelitian dibagi menjadi dua percobaan. Percobaan pertama adalah penelitian tentang pengaruh populasi tanaman pada produktivitas tanaman dan percobaan kedua adalah penelitian tentang pengaruh populasi tanaman pada konsumsi air tanaman. Hasil penelitian menunjukkan bahwa tanaman dengan satu bibit per lubang tanam memberikan respon terbaik terhadap pertumbuhan bayam (tinggi tanaman, daun angka), tetapi untuk produktivitas tanaman hasil terbaik ditunjukkan oleh tanaman dengan tiga bibit per lubang tanam. Konsumsi air terbanyak terjadi pada tanaman dengan satu bibit per lubang tanam. Ternyata, semakin banyak populasi maka semakin sedikit konsumsi air yang dibutuhkan. Hal ini disebabkan karena kondisi akar buruk pada populasi yang padat. Akar tanaman buruk akan mempengaruhi penyerapan air.

Kata kunci: hidroponik kit, lubang tanam, kerikil, nomor pembibitan

\footnotetext{
* Penulis untuk korespondensi. e-mail: wachjarade@yahoo.co.id
} 


\section{PENDAHULUAN}

Kandungan nutrisi yang cukup tinggi pada bayam dan rasanya yang cukup lezat menjadikan bayam sebagai salah satu komoditas sayuran yang banyak diminati masyarakat untuk dikonsumsi. Konsumsi bayam di Indonesia mengalami peningkatan dari tahun ke tahun. Budidaya bayam pun cukup mudah dilakukan. Bayam biasa diperbanyak secara generatif yaitu melalui bijinya. Bayam dapat dibudidayakan di tanah ber-pH netral baik di dataran tinggi maupun rendah (Hadisoeganda, 1996). Keuntungan - keuntungan ini memberikan peluang yang besar untuk melakukan usaha agribisnis bayam.

Permintaan bayam yang cukup tinggi belum dapat dipenuhi secara maksimal oleh banyak petani bayam. Pengalihan lahan pertanian menjadi lahan non pertanian mengurangi fungsi lahan untuk pertanian. Kualitas bayam yang dihasilkan petani pun masih kurang baik, sehingga kehilangan hasil yang diperoleh cukup tinggi. Semakin berkurangnya lahan pertanian dan rendahnya kualitas bayam yang dihasilkan para petani merupakan contoh masalah yang dihadapi dalam kegiatan budidaya sayuran bayam.

Hidroponik dapat menjadi suatu solusi untuk memecahkan masalah pertanian tersebut. Hidroponik dapat diartikan sebagai teknik budidaya tanaman dengan menggunakan media tanam selain tanah dan memanfaatkan air untuk menyalurkan unsur hara yang dibutuhkan ke setiap tanaman. Hidroponik juga memiliki beberapa keuntungan diantaranya adalah budidayanya yang tidak bergantung iklim, hasil panen yang kontinyu, dan perwatan tanaman yang lebih praktis (Lingga, 2007). Komoditas yang sering dibudidayakan dengan hidroponik adalah komoditas hortikultura. Komoditas hortikultura memiliki umur panen yang singkat dan morfologi yang kecil sehingga mudah dibudidayakan secara hidroponik. Alasan inilah mengapa hidroponik dapat menjadi salah satu teknik budidaya yang cocok untuk tanaman bayam.

Air merupakan unsur yang tidak dapat dihilangkan untuk keberlangsungan makhluk hidup termasuk tanaman. Pada teknik hidroponik, air adalah faktor penting karena unsur hara yang dibutuhkan tanaman diberikan melalui air. Meskipun air merupakan faktor penting untuk tanaman, penggunaannya juga harus dilakukan seefisien mungkin karena semakin berkurangnya sumber air bersih. Penghematan air pada teknik hidroponik berarti juga merupakan penghematan pada penggunaan pupuk, sehingga dapat mengurangi biaya produksi.

Efisiensi penggunaan air dapat dilakukan melalui penanaman bayam dengan jumlah populasi yang optimum. Populasi bayam umumnya berkisar 50 tanaman per $\mathrm{m}^{2}$ (Rubatzky dan Yamaguchi, 1999). Secara umum semakin besar populasi semakin banyak air yang dibutuhkan dan semakin rendah kualitas yang diperoleh dari satu individu tanaman. Berdasarkan penelitian Rachman dan Mahfudz (2007), pada tanaman tembakau contohnya, peningkatan populasi akan menurunkan ukuran daun, bobot tiap daun, tinggi tanaman, lingkar batang, dan jumlah daun yang dapat dipanen, tetapi tidak berpengaruh pada jumlah seluruh daun yang terbentuk dan mutu rasa tembakau. Hal ini disebabkan karena terjadinya kompetisi antara tanaman dalam memperebutkan air, zat hara, cahaya, dan faktor tumbuh pendukung lainnya. Sedangkan menurut Harjadi (1996) dengan pemupukan berat populasi yang lebih besar akan mendatangkan keefisienan penggunaan pupuk, karena tercapainya keefisienan penggunaan cahaya. Oleh karena itu, perlu diketahui populasi tanaman bayam yang paling optimum agar dapat menghemat penggunaan air dan pupuk serta menghasilkan produktivitas yang paling maksimum.

Penelitian ini bertujuan untuk mengetahui populasi optimum tanaman bayam pada teknik hidroponik yang menghasilkan produktivitas maksimum dan mengetahui pengaruh populasi terhadap kebutuhan air tanaman bayam pada teknik hidroponik.

\section{BAHAN DAN METODE}

Penelitian dilaksanakan di Parung Farm yang terletak di Jalan Raya Parung Nomor 546, Parung, Bogor, pada bulan April sampai dengan Mei 2011.

Bahan yang digunakan adalah benih bayam varietas Amaranth 936 white leaf, pupuk NPK mutiara, serta media tanam berupa kerikil.

Pada penelitian ini terdapat dua percobaan yaitu percobaan mengenai studi populasi terhadap produktivitas dan studi populasi terhadap kebutuhan air tanaman bayam. Rancangan percobaan yang digunakan pada kedua percobaan ini adalah Rancangan Kelompok Lengkap Teracak (RKLT) dengan satu faktor tiga ulangan. Faktor perlakuan yang digunakan yaitu jumlah bibit. Jumlah bibit yang digunakan adalah satu bibit, dua bibit, tiga bibit, dan empat bibit, sehingga terdapat 12 satuan percobaan yang terdapat pada masing-masing percobaan.

Data dianalisis menggunakan uji $\mathrm{F}$ pada taraf nyata 5\%. Jika tidak berbeda nyata, maka dilakukan uji lanjut dengan uji DMRT.

Pada budidaya tanaman bayam dengan teknik hidroponik ini terdapat dua tahap yaitu penyemaian dan 
pembesaran. Kegiatan penyemaian dan pembesaran dilakukan di dalam greenhouse. Dosis pupuk yang digunakan yaitu 3 gram per literair. Sistem hidroponik yang digunakan adalah sistem NFT modifikasi kerikil.

Pada tahap penyemaian dan pembesaran percobaan studi populasi terhadap produktivitas alat dan bahan bergabung dengan kegiatan produksi di Parung Farm yang dilakukan di bedengan. Sedangkan pada percobaan studi populasi terhadap kebutuhan air tanaman bayam, alat yang digunakan berupa hydroponic kit yang dibuat oleh penulis Hydroponic kit yang digunakan adalah hydroponic kit tipe statis yang terbuat dari pot plastik kecil berdiameter 40 $\mathrm{cm}$ dan botol air mineral bekas. Satu pot merupakan perwakilan dari masing-masing satuan percobaan. Pada satu pot tersebut dibuat lima lubang tanam yang masing-masing lubang berjarak $15 \mathrm{~cm}$, hal ini agar kondisi pada pot sesuai dengan kondisi pada bedengan. Di tengah pot diletakkan botol plastik yang berisi air larutan pupuk.

Benih bayam disemai di bedengan berukuran $2 \mathrm{~m} \times 8 \mathrm{~m}$ dengan media kerikil selama kurang lebih 14 hari. Ketebalan kerikil antara $3 \mathrm{~cm}-5 \mathrm{~cm}$. Sebelum penyemaian dipastikan kerikil dalam keadaan bersih dan tidak berlumut. Benih bayam disebar secara merata, kemudian ditutup dengan plastik selama dua hari Bedengan dibuat miring $5^{\circ}$ agar larutan nutrisi yang diberikan dapat menyebar merata dan tidak tergenang. Pada tahap penyemaian, dilakukan juga kegiatan pemeliharaan seperti pemupukan, pengendalian hama dan penyakit, dan pembersihan saluran irigasi.

Setelah tanaman bayam cukup besar, tanaman bayam siap dipindahtanamkan di media pembesaran dengan variasi jumlah bibit yang telah ditentukan. Tanaman bayam yang ditanam pada tahap pembesaran dipilih yang memiliki karakter fisik yang homogen dan tidak terserang hama penyakit. Tinggi tanaman bayam yaitu $4 \mathrm{~cm}$ dari pangkal batang sampai dengan titik tumbuh dan memiliki 4 daun. Jarak tanam yang digunakan adalah $15 \mathrm{~cm}$ x $15 \mathrm{~cm}$. Satu petak percobaan berukuran $2 \mathrm{~m} \times 1 \mathrm{~m}$. Bayam yang berumur 17 hari siap untuk dipanen. Bayam dicabut sampai ke akar dan dibersihkan dari kerikil.

Pengamatan tanaman bayam dilakukan 3 hari setelah transplanting pada 5 tanaman contoh dari setiap petak perlakuan dan dilakukan setiap 3 hari sekali. Peubah yang diamati adalah: (1) tinggi tanaman, (2) jumlah daun yang sudah membuka sempurna, (3) bobot basah dan bobot kering tanaman, tajuk dan akar tanaman ditimbang secara terpisah, (4) kadar air tanaman berdasarkan bobot basah, (5) volume air yang berkurang yaitu volume air awal dikurangi volume air yang tersisa di dalam wadah air pada hydroponic kit; volume air yang berkurang dibagi dengan jumlah individu tanaman merupakan kebutuhan air per tanaman, (6) luas permukaan daun per tanaman, luas permukaan daun dihitung saat pengamatan terakhir menggunakan metode gravimetri dengan menggunakan persamaan: $\mathrm{LD}=\mathrm{A} / \mathrm{B} \times \mathrm{LK}$ (LD: luas daun $\left(\mathrm{cm}^{2}\right)$, A: bobot daun (gram), B: bobot kertas (gram), LK: luas kertas $\left(\mathrm{cm}^{2}\right)$, (7) ILD (Indeks Luas Daun) dihitung dengan menggunakan persamaan $\mathrm{ILD}=\mathrm{LD} / \mathrm{Lt}(\mathrm{LD}=$ luas daun, $\mathrm{Lt}=$ Luas lahan yang ditumbuhi tanaman).

\section{HASIL DAN PEMBAHASAN}

Seluruh penanaman dilakukan di dalam greenhouse. Greenhouse yang digunakan adalah model piggy back system. Suhu greenhouse antara $26^{\circ} \mathrm{C}-43^{\circ} \mathrm{C}$ dan kelembaban udara sekitar $30 \%-80 \%$. Suhu greenhouse yang cukup tinggi saat siang hari dan kelembabannya yang rendah menjadikan tanaman bayam layu sesaat, namun saat suhu menurun dan kelembaban kembali meningkat di sore hari, tanaman bayam kembali segar.

Curah hujan saat penelitian pada bulan April adalah $176.5 \mathrm{~mm}$ dan meningkat pada bulan Mei menjadi $336.5 \mathrm{~mm}$.

\section{Studi Populasi Terhadap Produktivitas Tanaman Bayam}

Perlakuan jumlah bibit per lubang tanam tidak berpengaruh nyata terhadap tinggi tanaman bayam saat umur 12 dan 17 hari setelah pindah tanam (Tabel 1). Setiap kali dilakukan pengamatan tinggi tanaman yang paling tinggi adalah tanaman dengan perlakuan tiga bibit per lubang tanam.

Tabel 1. Tinggi Tanaman (cm) saat 3-17 HST

\begin{tabular}{lcccc}
\hline \multirow{2}{*}{$\begin{array}{l}\text { Umur } \\
\text { (HST) }\end{array}$} & \multicolumn{4}{c}{ Jumlah bibit per lubang tanam } \\
\cline { 2 - 5 } & 1 & 2 & 3 & 4 \\
\hline 3 & $3.00 \mathrm{~b}$ & $1.92 \mathrm{~b}$ & $5.06 \mathrm{a}$ & $3.12 \mathrm{~b}$ \\
6 & $4.12 \mathrm{~b}$ & $3.14 \mathrm{~b}$ & $6.31 \mathrm{a}$ & $4.38 \mathrm{ab}$ \\
9 & $5.95 \mathrm{~b}$ & $4.65 \mathrm{~b}$ & $8.33 \mathrm{a}$ & $6.17 \mathrm{ab}$ \\
12 & 8.29 & 7.37 & 12.05 & 10.07 \\
15 & $13.01 \mathrm{~b}$ & $11.77 \mathrm{~b}$ & $17.58 \mathrm{a}$ & $15.24 \mathrm{ab}$ \\
17 & 21.5 & 19.26 & 23.62 & 20.32 \\
\hline
\end{tabular}

Keterangan : angka yang diikuti oleh huruf yang berbeda pada baris yang sama menunjukkan berbeda nyata berdasarkan Uji DMRT 5\% 
Perlakuan jumlah bibit per lubang tanam berpengaruh sangat nyata terhadap jumlah daun tanaman yang berumur 17 hari setelah pindah tanam. Hal ini dapat dilihat pada Tabel 2. Tanaman yang ditanam dengan jumlah bibit satu per lubang tanam menghasilkan jumlah daun yang paling banyak sejak awal pindah tanam sampai dengan waktu panen.

Perlakuan jumlah bibit per lubang tanam berpengaruh sangat nyata terhadap peubah bobot basah per tanaman, bobot basah tajuk, dan luas permukaan daun. Pada tiap peubah angka tertinggi ada pada perlakuan jumlah bibit satu per lubang tanam, kecuali untuk peubah bobot basah per $\mathrm{m}^{2}$ angka tertinggi ada pada perlakuan tiga bibit per lubang tanam (Tabel 3).

Tanaman yang ditanam satu bibit per lubang tanam dengan jarak tanam $15 \mathrm{~cm}$ x $15 \mathrm{~cm}$ memiliki populasi per meter persegi sebanyak 44 tanaman bayam, tanaman bayam yang ditanam dengan dua bibit per lubang tanam memiliki populasi per meter persegi 88 tanaman, tanaman bayam yang ditanam dengan tiga bibit per lubang tanam memiliki populasi per meter persegi 132 tanaman, dan tanaman bayam yang ditanam dengan empat bibit per lubang tanam memiliki populasi per meter persegi 176 tanaman Bobot basah tanaman per meter persegi paling besar didapat dari tanaman yang ditanam dengan tiga bibit per lubang tanam, yaitu sebesar 1501.7 gram. Populasi yang menghasilkan bobot basah tanaman per meter persegi terbesar adalah populasi dengan 132 tanaman bayam per meter persegi.

Dilakukan uji lanjut kontras ortoghonal dan polinomial untuk melihat keefektifan pengaruh jumlah bibit per lubang tanam terhadap bobot basah tanaman per meter persegi.

Hasil uji lanjut kontras orthogonal menunjukkan tanaman yang ditanam dengan dua bibit per lubang tanam menghasilkan bobot yang nyata lebih ringan dibandingkan dengan tanaman yang ditanam

Tabel 2. Jumlah Daun saat 3-17 HST

\begin{tabular}{lcccl}
\hline Umur & \multicolumn{4}{c}{ Jumlah bibit per lubang tanam } \\
\cline { 2 - 5 } (HST) & 1 & 2 & 3 & \multicolumn{1}{c}{4} \\
\hline 3 & $4.13 \mathrm{a}$ & $3.82 \mathrm{~b}$ & $4.02 \mathrm{a}$ & $3.93 \mathrm{ab}$ \\
6 & 5.47 & 5.33 & 5.29 & 4.85 \\
9 & 9.27 & 6.67 & 8.56 & 6.7 \\
12 & $11.93 \mathrm{a}$ & $8.53 \mathrm{bc}$ & $10.11 \mathrm{ab}$ & $7.56 \mathrm{c}$ \\
15 & $13.53 \mathrm{a}$ & $9.87 \mathrm{~b}$ & $9.56 \mathrm{~b}$ & $7.83 \mathrm{~b}$ \\
17 & $17.07 \mathrm{a}$ & $10.77 \mathrm{~b}$ & $10.6 \mathrm{~b}$ & $8.32 \mathrm{c}$ \\
\hline
\end{tabular}

Keterangan : angka yang diikuti oleh huruf yang berbeda pada baris yang sama menunjukkan berbeda nyata berdasarkan Uji DMRT 5\% dengan tiga dan empat bibit per lubang tanam.

Hasil uji lanjut kontras polinomial menunjukkan pola respon dari perlakuan jumlah bibit per lubang tanam mengikuti pola linier.

\section{Studi Populasi terhadap Kebutuhan Air Tanaman Bayam}

Perlakuan jumlah bibit per lubang tanam pada percobaan ini tidak berpengaruh nyata terhadap tinggi tanaman bayam (Tabel 4). Tinggi tanaman bayam dengan perlakuan satu bibit per lubang tanam yang memberikan respon terbaik.

Perlakuan jumlah bibit per lubang tanam tidak mempengaruhi secara nyata peubah jumlah daun saat tanaman (Tabel 5).

Perlakuan jumlah bibit per lubang tanam berpengaruh nyata terhadap seluruh peubah panen, kecuali pada kadar air akar dan kadar air tajuk (Tabel 6). Pada seluruh peubah yang memberikan respon nyata, nilai tertinggi selalu ada pada perlakuan jumlah bibit satu per lubang tanam.

Populasi adalah jumlah individu sejenis di dalam suatu areal. Peningkatan jumlah bibit per lubang tanam berarti meningkatkan populasi tanaman dan diharapkan akan meningkatkan produktivitas tanaman bayam per meter persegi. Besarnya populasi tanaman akan mempengaruhi faktor tumbuh yang

Tabel 3. Peubah Panen

\begin{tabular}{|c|c|c|c|c|}
\hline \multirow[t]{2}{*}{ Peubah Panen } & \multicolumn{4}{|c|}{ Jumlah bibit per lubang tanam } \\
\hline & 1 & 2 & 3 & 4 \\
\hline $\begin{array}{l}\text { Bobot basah per } \\
\operatorname{tanaman}(\mathrm{g})\end{array}$ & $24.43 a$ & $13.94 b$ & $12.28 \mathrm{~b}$ & $10.03 b$ \\
\hline $\begin{array}{l}\text { Bobot basah tajuk } \\
\text { (g) }\end{array}$ & $21.16 \mathrm{a}$ & $14.57 b$ & $10.57 b$ & $8.92 b$ \\
\hline Bobot basah akar (g) & $3.27 \mathrm{a}$ & $2.61 \mathrm{ab}$ & $1.62 \mathrm{bc}$ & $1.12 \mathrm{c}$ \\
\hline $\begin{array}{l}\text { Bobot basah per } \\
\mathrm{m}^{2}(\mathrm{~g})\end{array}$ & 821.7 & 795.0 & 1501.7 & 1383.3 \\
\hline $\begin{array}{l}\text { Bobot kering tajuk } \\
(\mathrm{g})\end{array}$ & $2.03 \mathrm{a}$ & $1.16 \mathrm{ab}$ & $0.8 \mathrm{~b}$ & $0.54 \mathrm{~b}$ \\
\hline $\begin{array}{l}\text { Bobot kering akar } \\
(\mathrm{g})\end{array}$ & $0.31 \mathrm{a}$ & $0.22 \mathrm{ab}$ & $0.2 \mathrm{ab}$ & $0.1 b$ \\
\hline $\begin{array}{l}\text { Luas Permukaan } \\
\text { Daun }(\mathrm{cm})\end{array}$ & $632.13 \mathrm{a}$ & $340 \mathrm{~b}$ & $347.45 b$ & $241.97 b$ \\
\hline ILD & $2.81 b$ & $1.51 \mathrm{~b}$ & $1.54 \mathrm{~b}$ & $1.07 \mathrm{~b}$ \\
\hline
\end{tabular}


Tabel 4. Tinggi tanaman (cm) saat 3-17 HST

\begin{tabular}{lcccc}
\hline \multirow{2}{*}{$\begin{array}{l}\text { Umur } \\
\text { HST })\end{array}$} & \multicolumn{4}{c}{ Jumlah bibit per lubang tanam } \\
\cline { 2 - 5 } & 1 & 2 & 3 & 4 \\
\hline 3 & 2.95 & 2.11 & 2.66 & 2.77 \\
6 & 3.72 & 3.14 & 3.27 & 3.43 \\
9 & 4.21 & 3.69 & 3.85 & 3.86 \\
12 & 5.92 & 4.49 & 5.17 & 4.49 \\
15 & 6.95 & 4.97 & 5.72 & 5.17 \\
17 & 8.06 & 5.73 & 6.49 & 5.89 \\
\hline
\end{tabular}

Keterangan : angka yang diikuti oleh huruf yang berbeda pada baris yang sama menunjukkan berbeda nyata berdasarkan Uji DMRT 5\%

diterima tanaman seperti air dan cahaya. Semakin banyak populasi tanaman semakin sedikit factor tumbuh yang individu yang ada pada areal tersebut disebabkan terjadinya persaingan. Konsumsi air dan cahaya pada tanaman akan terpenuhi secara optimum dengan populasi tanaman yang juga optimum. Selain itu dengan populasi optimum pemakaian lahan lebih efisien dan sebagai tindak pencegahan terhadap serangan hama dan penyakit pada tanaman.

Pengamatan yang dilakukan pada penelitian ini adalah terhadap pertumbuhan vegetatiftanaman bayam. Pertumbuhan berarti pembelahan sel (peningkatan jumlah) dan pembesaran sel (peningkatan ukuran) (Gardner et al., 1991). Faktor tumbuh seperti air dan cahaya akan sangat mempengaruhi pertumbuhan tanaman. Pertumbuhan tanaman akan baik jika air dan cahaya yang didapat sesuai dengan kebutuhan tanaman. Tanaman yang ditanam dengan tingkat populasi yang tepat konsumsi air dan cahayanya dapat dipenuhi sesuai kebutuhan. Pertumbuhan tanaman akan maksimal sehingga diperoleh pula produktivitas yang maksimum.

Pada kedua percobaan, berdasarkan hasil sidik ragam pada tanaman bayam, jumlah bibit tidak berpengaruh nyata terhadap tinggi tanaman saat panen (17 HST). Secara teori tanaman yang ditanam dengan populasi yang tinggi menghasilkan tanaman yang lebih tinggi karena adanya proses etiolasi. Cahaya memiliki pengaruh nyata terhadap pertumbuhan batang. Tanaman yang ternaungi pada tegakan yang rapat biasanya memiliki batang yang lebih tinggi. Pengaruh naungan tersebut disebabkan oleh peningkatan auksin yang bekerja secara sinergis dengan giberelin (Gardner et al., 1991). Pada percobaan studi populasi tanaman terhadap konsumsi air tanaman bayam, teori etiolasi tidak berlaku karena tanaman yang ditanam dengan satu bibit per lubang tanam memiliki tinggi tanaman
Tabel 5. Jumlah daun saat 3-17 HST

\begin{tabular}{lcccc}
\hline Umur & \multicolumn{4}{c}{ Jumlah bibit per lubang tanam } \\
\cline { 2 - 5 }$($ HST $)$ & 1 & 2 & 3 & 4 \\
\hline 3 & 4.13 & 4.03 & 4.16 & 3.95 \\
6 & 5.33 & 4.53 & 4.93 & 4.38 \\
9 & 6.67 & 5.50 & 6.05 & 4.93 \\
12 & 9.87 & 6.50 & 7.18 & 5.26 \\
15 & 10.33 & 6.27 & 6.20 & 5.717 \\
17 & 10.13 & 6.50 & 5.22 & 5.317 \\
\hline
\end{tabular}

Keterangan : angka yang diikuti oleh huruf yang berbeda pada baris yang sama menunjukkan berbeda nyata berdasarkan Uji DMRT 5\%

tertinggi. Hal ini diduga karena tanaman yang ditanam satu bibit per lubang tanam pada percobaan kedua keadaan fisiknya lebih sehat dibandingkan tanaman pada perlakuan lain yang banyak terserang penyakit rebah kecambah, sehingga pertumbuhan batangnya lebih optimum.

Jumlah bibitberpengaruh sangat nyata terhadap jumlah daun saat panen (17 HST) pada percobaan studi populasi tanaman terhadap produktivitas, tetapi tidak berpengaruh pada percobaan studi populasi tanaman terhadap konsumsi air tanaman bayam. Jumlah daun terbanyak pada kedua percobaan terdapat pada perlakuan satu bibit per lubang tanam. Pertumbuhan daun sangat dipengaruhi oleh suhu, kelembaban, dan ketersediaan cahaya. Peningkatan populasi

Tabel 6. Peubah panen

\begin{tabular}{lrrrr}
\hline Peubah Panen & \multicolumn{4}{c}{ Jumlah bibit per lubang tanam } \\
\cline { 2 - 5 } & \multicolumn{1}{c}{1} & \multicolumn{1}{c}{2} & \multicolumn{1}{c}{3} & \multicolumn{1}{c}{4} \\
\hline $\begin{array}{l}\text { Bobot basah per } \\
\text { tanaman (g) }\end{array}$ & $6.11 \mathrm{a}$ & $2.78 \mathrm{~b}$ & $2.01 \mathrm{~b}$ & $2.14 \mathrm{~b}$ \\
Bobot basah tajuk (g) & $5.16 \mathrm{a}$ & $2.27 \mathrm{~b}$ & $1.71 \mathrm{~b}$ & $1.77 \mathrm{~b}$ \\
Bobot basah akar (g) & $0.95 \mathrm{a}$ & $0.51 \mathrm{~b}$ & $0.3 \mathrm{~b}$ & $0.37 \mathrm{~b}$ \\
$\begin{array}{l}\text { Bobot kering tajuk } \\
\text { (g) }\end{array}$ & $0.55 \mathrm{a}$ & $0.23 \mathrm{~b}$ & $0.19 \mathrm{~b}$ & $0.2 \mathrm{~b}$ \\
$\begin{array}{l}\text { Bobot kering akar (g) } \\
\text { Luas Permukaan }\end{array}$ & $0.18 \mathrm{a}$ & $0.11 \mathrm{~b}$ & $0.05 \mathrm{c}$ & $0.1 \mathrm{bc}$ \\
$\begin{array}{l}\text { Daun (cm }{ }^{2} \text { ) } \\
\text { Kebutuhan air per }\end{array}$ & $395.67 \mathrm{a}$ & $218.5 \mathrm{~b}$ & $146.22 \mathrm{~b}$ & $89.83 \mathrm{~b}$ \\
tanaman (ml) & & & & \\
Kadar Air Akar (\%) & 81.52 & 80.03 & 81.39 & 79.25 \\
Kadar Air Tajuk (\%) & 89.41 & 87.88 & 88.06 & 90.9 \\
\hline
\end{tabular}

Keterangan : angka yang diikuti oleh huruf yang berbeda pada baris yang sama menunjukkan berbeda nyata berdasarkan Uji DMRT $5 \%$ 
tanaman akan mengurangi ketersediaan cahaya dan pada akhirnya akan mengurangi pembentukan pucuk. Meningkatnya populasi akan meningkatkan kebutuhan cahaya untuk proses fotosintesis karena makin beratnya persaingan antara tanaman dalam memperebutkan cahaya. Hal tersebut dikaitkan dengan persaingan untuk mendapatkan hasil asimilasi, karena fotosintesis berkurang dalam tegakan yang rapat (Gardner et al., 1991). Pada populasi tanaman yang rapat, banyak permukaan daun yang saling menutup, sehingga menghambat proses fotosintesis. Proses fotosintesis yang terhambat akan berdampak pada jumlah fotosintat yang dihasilkan yang nantinya akan digunakan sebagai bahan pembentukan daun.

Luas permukaan daun secara nyata juga dipengaruhi oleh populasi tanaman. Tanaman dengan jumlah individu paling sedikit, yaitu satu bibit per lubang tanam nyata menghasilkan daun dengan permukaan yang paling luas, pada kedua percobaan. Permukaan daun yang luas, efektif dalam menangkap cahaya dan cepat dalam pengambilan $\mathrm{CO}_{2}$ untuk bahan dasar proses fotosintesis, karena permukaan daun merupakan organ utama tumbuhan untuk melakukan fotosintesis. Oleh karena itu, tanaman dengan satu bibit per lubang tanam memiliki penampilan fisik yang paling baik karena memiliki permukaan daun yang luas.

Secara rasional produktivitas tanaman bayam akan meningkat seiring dengan meningkatnya populasi tanaman. Akan tetapi, ada satu titik populasi tanaman yang sudah jenuh sehingga tanaman tidak lagi dapat bersaing dan secara berangsur produktivitas akan menurun. Bertambahnya jumlah bibit per lubang tanam di atas populasi jenuh cenderung meningkatkan persaingan tanaman, baik antar tanaman dalam satu lubang tanam maupun antar lubang tanam yang akan berdampak pada penurunan hasil (Masdar, 2006). Pada tanaman bayam empat bibit per lubang tanam hasil produksi lebih rendah dibandingkan dengan tiga bibit per lubang tanam. Hal tersebut diduga pada populasi tanaman empat bibit per lubang tanam merupakan titik jenuh populasi tanaman bayam yang dibudidayakan secara hidroponik sistem NFT modifikasi kerikil.

Hasil panen tanaman merupakan akibat dari penimbunan hasil bersih asimilasi $\mathrm{CO}_{2}$ selama pertumbuhan. Asimilasi $\mathrm{CO}_{2}$ merupakan hasil penyerapan energi matahari dan akibat radiasi matahari. Oleh karena itu, faktor utama yang mempengaruhi hasil panen ialah radiasi matahari yang diabrsorbsi. Populasi yang terlalu rapat, banyak daun yang saling menutup sehingga tidak efisien dalam penyerapan cahaya matahari. Oleh sebab itu, pada tanaman dengan empat bibit per lubang tanam terjadi penurunan produktivitas. Tanaman bayam dengan satu bibit per lubang tanam memiliki penampilan fisik yang paling baik karena lebih efisien dalam penyerapan cahaya matahari.

Tanaman yang ditanam dengan tiga bibit per lubang tanam menghasilkan produksi per meter persegi yang paling tinggi dibandingkan populasi tanaman yang lainnya. Akan tetapi, selain memiliki produktivitas yang tinggi, menanam tanaman dengan populasi 3 bibit per lubang tanam juga membutuhkan jumlah bibit yang lebih banyak dibandingkan menanam bayam satu atau dua bibit per lubang tanam yang juga akan meningkatkan biaya produksi. Berdasarkan kriteria investasi yang dihitung, populasi dengan tiga bibit per lubang memberikan keuntungan yang paling tinggi dibandingkan perlakuan jumlah bibit lainnya. Biaya investasi akan kembali setelah kurang lebih usaha berjalan selama 4.35 bulan.

Dibandingkan dengan budidaya tanaman bayam secara konvensional dengan produktivitas $2 \mathrm{~kg}$ per $^{2}$, menanambayam dengan teknik hidroponik lebih mahal biaya investasinya. Akan tetapi, keuntungan budidaya bayam secara hidroponik lebih besar dibandingkan budidaya bayam secara konvensional. Hal ini disebabkan harga bayam yang dibudidayakan dengan teknik hidroponik lebih tinggi karena memiliki pangsa pasar masyrakat menengah ke atas. Keuntungan usaha budidaya tanaman bayam secara hidropnik lebih tinggi 28.85 juta rupiah dibandingkan usaha budidaya tanaman bayam secara konvensional.

Konsumsi air pada percobaan ini diartikan sebagai jumlah air yang digunakan tanaman untuk proses evapotranspirasi setelah pindah tanam dan selama ada pada fase pembesaran. Evapotranspirasi (ET) merupakan gabungan dari proses evaporasi dan transpirasi. Evaporasi adalah proses menguapnya air dari permukaan media, sedangkan transpirasi adalah proses menguapnya air dari organ tanaman terutama daun. Pada percobaan ini tanaman yang ditanam dengan satu bibit per lubang tanam mengkonsumsi air yang paling banyak, disusul oleh dua bibit per lubang tanam, tiga bibit per lubang tanam, dan selanjutnya empat bibit per lubang tanam.

Penampilan individu tanaman bayam yang terbaik dihasilkan dari tanaman yang ditanam satu bibit per lubang tanam, meskipun bobot tanaman per pot paling tinggi adalah tanaman yang ditanam dengan 4 bibit per lubang tanam.

Salah satu faktoryang mempengaruhikonsumsi air adalah pertumbuhan akar. Menurut Gardner et al. (1991), faktor-faktor yang mempengaruhi pertumbuhan akar diantaranya adalah genotipe, persaingan tanaman, penghilangan daun, atmosfer media tumbuh, $\mathrm{pH}$ media 
tumbuh, temperatur media tumbuh, kesuburan media tumbuh, air, dan daya mekanik dan fisik. Faktor-faktor yang diduga mempengaruhi pertumbuhan akar pada percobaan ini adalah persaingan tanaman, atmosfer media tumbuh, dan air.

Pada percobaan ini semakin besar populasi ternyata semakin sedikit air yang diserap tanaman. Hal ini diduga karena pada lubang tanam dengan bibit yang banyak, pertumbuhan akar tanaman terhambat sehingga berpengaruh terhadap penyerapan air dan unsur hara. Setelah pindah tanam ke fase pembesaran akar harus mulai beradaptasi di media yang baru. Tanaman yang ditanam dengan banyak individu pada satu lubang tanam, akarnya sulit berkembang dan beradaptasi di media yang baru itu. Ujung dan bulu akar sulit tumbuh dan berkembang, padahal organ tersebut adalah organ yang utama dalam penyerapan air dan mineral. Akar tidak berkembang sehingga menurunkan bobot basah maupun bobot kering akar dan mempengaruhi penyerapan air dan unsur hara.

Akar tanaman pada percobaan ini pun berwarna coklat, sedangkan akar yang sehat menurut Resh (2004) berwarna putih dan berserat banyak. Akar berwarna coklat dapat menjadi indikator bahwa pada atmosfer sekitar kerikil kekurangan unsur oksigen. Oksigen sangat esensial untuk proses metabolisme, termasuk transport dan penyerapan aktif (Gardner et al., 1991). Tanaman yang di sekitar akarnya tidak terpenuhi kadar oksigen secara cukup, pertumbuhan akarnya akan terganggu dan mempengaruhi penyerapan air dan unsur hara yang diberikan. Selain disebabkan oleh kekurangan oksigen akar berwarna coklat pada tanaman bayam juga disebabkan serangan Phytium sp. Infeksi cendawan Phytium sp. dapat menyebabkan akar tanaman berwarna coklat dan tanaman menjadi kerdil (Resh, 2004).

Pada penelitian ini belum dapat diketahui berapa konsumsi air yang tepat untuk tanaman bayam yang ditanam dengan teknik hidroponik sistem substrat pada media kerikil. Selain faktor pertumbuhan akar, faktor lain yang mempengaruhi konsumsi air tanaman adalah sistem hidroponik yang digunakan. Sistem hidroponik yang digunakan masih sangat sederhana, sehingga mungkin saja ada kesalahan saat percobaan seperti adanya air hujan yang masuk ke hydroponic kit. Walaupun percobaan dilakukan di dalam greenhouse tetapi masih ada air hujan yang masuk meskipun sedikit, karena saat itu curah hujan yang cukup tinggi juga disertai angin kencang. Selain masuknya air hujan, lubang pengairan pada botol air mineral yang besarnya tidak sama juga diduga mempengaruhi konsumsi air tanaman bayam. Jumlah air yang dibutuhkan tanaman tidak tersedia sehingga tanaman mengalami kesulitan air yang dibutuhkan. Hal tersebut disebabkan oleh lubang pengairan yang kecil dan tidak sama ukurannya dari tiap satuan percobaan.

\section{KESIMPULAN}

Populasi tanaman bayam dengan tiga bibit per lubang tanam menghasilkan pertumbuhan dan produktivitas per satuan luas yang lebih tinggi dibandingkan dengan populasi tanaman lainnya. Populasi tanaman bayam hingga empat bibit per lubang tanam masih meningkatkan produktivitas per satuan luas.

Terdapat perbedaan dalam konsumsi air untuk pertumbuhan tanaman bayam dengan berbedanya populasi tanaman. Semakin banyak populasi tanaman hingga empat bibit per lubang tanam semakin sedikit konsumsi air.

Kriteria investasi terbaik dihasilkan dari tanaman bayam yang ditanam tiga bibit per lubang tanam dengan Nilai R/C 3.29 dan Payback Period 4.35 bulan.

\section{DAFTAR PUSTAKA}

Gardner, P. F., Pearce, R.B., Mitchell R.L. 1991. Fisiologi Tanaman Budidaya (diterjemahkan dari: Phisiology of Crop Plants, penerjemah: Herawati Susilo). Penerbit Universitas Indonesia. Jakarta. 428 hal.

Hadisoeganda, R.W.W. 1996. Bayam Sayuran Penyangga Petani di Indonesia. Balai Penelitian Tanaman Sayuran. Bandung.

Harjadi, S.S. 1996. Dasar-dasar Agronomi. Gramedia. Jakarta.

Lingga, P. 2007. Hidroponik Bercocok Tanam Tanpa Tanah. Penebar Swadaya. Jakarta.

Masdar. 2006. Pengaruh jumlah bibit tanam dan umur bibit terhadap pertumbuhan reproduktif tanaman padi pada irigasi tanpa penggenangan. Jurnal Dinamika Pertanian 21 (2):121 - 126.

Rachman A., Mahfudz. 2007. Pengaruh populasi tanaman terhadap sifat agronomis serta kadar c1 daun tembakau virginia rajangan pada tanah vertisols di Bojonegoro. Jurnal Litri 9(4): 1-6.

Rubatzky, E., Yamaguchi, M. 1999. Sayuran Dunia: Prinsip, Produksi, dan Gizi, Jilid 3(diterjemahkan dari: World Vegetables: Principles, Production, and Nutritive Values, penerjemah: C. Herison). Penerbit Institut 
Bul. Agrohorti 1 (1) : 127 - 134 (2013)

Teknologi Bandung. Bandung. 320 hal.

Untung, O. 2004. Hidroponik Sayuran Sistem NFT (Nutrient Film Technique). Penebar Swadaya. Jakarta. 